\title{
É preciso diminuir a distância entre o que se diz e o que se faz: \\ Paulo Freire e a Pedagogia da Esperança
}
It is fundamental to decrease the distance between what we say and what we do:

Paulo Freire and the Pedagogy of Hope

Es necesario reducir la distancia entre lo que se dice y lo que se hace: Paulo Freire y la pedagogía de la esperanza

\section{MARINEIDE DE OLIVEIRA GOMES*}

Universidade Católica de Santos, Santos- SP, Brasil.

\begin{abstract}
RESUMO: Diante dos retrocessos políticos do Governo Federal eleito em 2018, com os ataques à educação eà cultura, com a desqualificação da vida e da obra de Paulo Freire, no quadro de desmonte dos direitos sociais, torna-se imprescindível atualizar o legado freiriano. O artigo recupera aspectos da coerência entre teoria e prática de Paulo Freire como gestor público, em especial, como secretário de Educação do município de São Paulo (1989-1991), na perspectiva de reacender a esperança da interpelação na história, que sujeitos concretos fazem em realidades também concretas.

Palavras-chave: Paulo Freire. Gestão pública da educação. Teoria e prática freireana.
\end{abstract}

\begin{abstract}
Due to the political setbacks from the Federal Government elected in 2018, with attacks toward education and culture, and with the disqualification of Paulo Freire's life and work, in the context of dismantling social rights, updating the Freirean legacy is nothing but essential. The article recovers aspects of the coherence between Paulo Freire's theory and practice as a public manager, particularly,
\end{abstract}

* Mestre e doutora em Educação pela Universidade de São Paulo. Realizou pós-doutoramento em Educação na Universidade Católica Portuguesa. É professora da Universidade Católica de Santos e líder do Observatório de Profissionais da Educação: Políticas e Pesquisa-Formação. E-mail: <marineide.gomes@unisantos.br>. 
as Secretary of Education in the city of São Paulo (1989-1991), in the perspective of rekindling the hope interpellation in History, where real citizens act in actualities just as real.

Keywords: Paulo Freire. Public management in education. Freirean theory and practice.

RESUMEN: Ante los retrocesos políticos del Gobierno Federal electo en 2018, con los ataques a la educación y la cultura, con la descalificación de la vida y obra de Paulo Freire, en el contexto del desmantelamiento de los derechos sociales, se torna imprescindible la actualización del legado freireano. El artículo recupera aspectos de la coherencia entre teoría y práctica de Paulo Freire como gestor público, en particular como Secretario de Educación del municipio de São Paulo (1989-1991), con la perspectiva de reavivar la esperanza de la interpelación por parte de la historia, que es hecha por sujetos concretos en realidades también concretas.

Palabras clave: Paulo Freire. Gestión de la educación pública. Teoría y práctica freireana.

\section{Introdução}

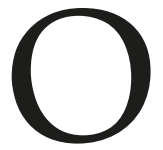

Brasil atravessa uma das mais sérias crises políticas de sua história, com desdobramentos em diferentes campos, em especial, nos campos social, econômico cultural e educacional, após a eleição do Governo Federal em 2018 que empreende desmonte generalizado dos direitos sociais agudizado com as consequências da pandemia do Covid 19, seja pelo despreparo e vazio de orientações e ações efetivas de saúde pública e de articulação político-federativa, seja pela condição brasileira (pré-existente) de gigantesca desigualdade social, que penaliza ainda mais as populações mais vulneráveis. Desde o início do atual Governo, os ataques à educação tiveram como símbolo o Patrono da Educação Brasileira (BRASIL, 2012), Paulo Freire, na campanha governamental com toda sorte de desqualificações de sua vida e obra, em nome da moralização da educação e dos costumes de um autor que dispensa apresentações, considerado patrimônio brasileiro, com reconhecimento e valorização mundiais.

O Brasil, país de capitalismo periférico, diverso e desigual, produziu e segue produzindo profundas desigualdades - sendo o $7^{\circ}$ país mais desigual do mundo (atrás de países africanos), com a característica marcante de grande concentração de riqueza e de renda, entre pobres e ricos, entre negros e brancos e entre mulheres e homens (OXFAM BRASIL, 2018). 
Mesmo considerando os "respiros democráticos", pós Constituição Federal de 1988 (CF/1988), que fez um pacto com relação aos direitos civis e políticos por uma democracia real, com políticas de proteção social, assiste-se, na atualidade, a uma situação generalizada de regressão social e de direitos, resultado também da herança escravista, racista e patriarcal (SOUSA-SANTOS, 2018), lembrando que o Brasil foi o último país do mundo a abolir a escravidão (formal), permanecendo, na prática, um racismo estrutural que dificulta a mobilidade social e o exercício da cidadania.

Como marcas da política brasileira podemos destacar a dificuldade de manutenção de processos democráticos e que apresenta ondas pendulares (AVRITZER, 2019, 2016), resultando em uma democracia fragilizada; e as instituições, em geral, em retaguarda, quando seria necessário, na situação atual, estarem na vanguarda da garantia de direitos. Dessa forma, juntamente com a pandemia do Covid19, o isolamento social e suas consequências, como o desemprego, o subemprego, a crescente situação de miséria de populações mais pobres, numa condição própria de genocídio intencionalizado, temos um cenário de pandemônio com um governo que tem por projeto a destruição e o leilão do País ao capital predatório nacional e internacional e o extermínio dos que apresentam pensamento divergente (FREI BETTO, 2020).

Do ponto de vista da política educacional, a desigualdade social se faz sentir na desigualdade educacional (DUBET, 2008). O País apresenta um quadro desolador de 7\% da população analfabeta e $29 \%$ da população analfabeta funcional ${ }^{1}$ (IBGE, 2019). As políticas sociais (entre elas, as políticas educacionais), em geral, apresentam-se como estratégias de alívio da pobreza (ALGEBAILE, 2009), na contramão de políticas de caráter universalizante, com ações pouco coordenadas nas esferas de governo, sendo importante reconhecer que a educação nunca foi prioridade no país e os profissionais da educação não são considerados interlocutores legítimos na definição das políticas públicas, uma vez que tais políticas são gestadas de fora para dentro das escolas, são descontínuas e pouco avaliadas, apresentando-se, em geral, como políticas de governo e não como políticas de Estado.

E qual a razão de Paulo Freire ser tão importante nos tempos de hoje? Para além da grandeza de sua obra, especialmente por ter vivido num período autoritário da ditadura civil-militar do país (1964-1985) e não ter desistido de seus ideais, na perspectiva do direito à educação, após ter sofrido prisão e exílio político (1964-1980) e acreditar no potencial da educação (que, ao completar 50 anos da sua obra mais conhecida Pedagogia do Oprimido, o terceiro livro mais citado em trabalhos acadêmicos da área de Ciências Humanas no mundo) é em Paulo Freire, em sua teoria de conhecimento e coerência de vida que nos inspiramos.

Paulo Freire dedicou-se "aos esfarrapados do mundo" (FREIRE, 1978), à luta pela justiça social e representa motivo de alento para aqueles que acreditam em seus propósitos e em uma educação emancipatória. Como autor e ator comprometido com os oprimidos e a humanização - ao não dissociar educação e política e lutar pelas injustiças, tendo o diálogo e a leitura de mundo e o entendimento de que conhecer é tarefa coletiva - como 
peças-chave de sua teoria, enfatizou a radicalidade do papel da libertação para a justiça e as transformações sociais.

Reafirmamos que Paulo Freire é o autor que mais conta com reconhecimento no mundo, colecionando títulos dentro e fora do País e influenciou muitos autores, entre eles, os autores que se alinham às pedagogias críticas. No Brasil, há apreensões diferenciadas pelos meios acadêmicos e populares de sua obra e atualmente, conforme já explicitamos, considerar Paulo freire como inimigo público número um do País no atual (des)governo guarda coerência com os propósitos de governos autoritários pela ameaça da alfabetização cultural e política de sujeitos históricos e criadores de cultura, que, quando conscientizados e organizados, podem transformar a sociedade (BOFF apud GADOTTI; ABRÃ̃O, 2012, p. 107).

Recriá-lo (e não imitá-lo) é importante ainda pela crença na potência, no inacabamento e na capacidade de "ser mais" como vocação ontológica humana (FREIRE, 2003), resultado de uma práxis que envolve ação e reflexão no mundo e sobre o mundo, por meio da problematização, norteadora do processo educativo e do desenvolvimento da consciência crítica e da relação dialógica de ensinar aprendendo. Para recriá-lo, consideramos importante recuperar a experiência de Paulo Freire gestor, que se inicia em Pernambuco, como superintendente do Sesi (Serviço Social da Indústria), no período de 1954 a 1957 e finaliza em São Paulo, como secretário Municipal de Educação: 1989-1991).

\section{Paulo Freire gestor: coerência entre teoria e prática}

A gênese de Paulo Freire gestor público se inicia em Recife (PE), quando ele assume a Superintendência do Serviço Social da Indústria (Sesi), na década de 1950, com intenção de transformar a educação (adestração) para o trabalho em educação libertadora; e no contato direto com os trabalhadores e suas realidades, buscou superar o assistencialismo que imperava no sistema " $\mathrm{S}$ " ${ }^{2}$, de mera preparação de trabalhadores para as exigências do mundo do trabalho, pela via da democratização da educação (FREIRE, 1992).

Na sequência, colabora com o governo de Miguel Arraes, no Conselho Estadual de Educação de Pernambuco. Atuou ainda como professor de educação básica, no Serviço de Extensão Cultural da Universidade Federal de Pernambuco e no Movimento de Cultura Popular (ainda em Recife), em que pode experienciar os círculos de cultura (pelo exercício do diálogo, da participação, do respeito ao outro e da atuação coletiva). Teve participação preponderante na coordenação do Programa Nacional de Alfabetização, na preparação da criação da Campanha Nacional contra o Analfabetismo, em Brasília, no governo de João Goulart e, nesse período, coloca em prática sua teoria de conhecimento sobre a educação de adultos, de caráter popular, que valoriza uma relação horizontalizada entre educadores e educandos, considera os saberes orgânicos dos sujeitos e das localidades e a leitura de mundo dos educandos, antes da leitura de palavras. Tal leitura de mundo oferece condições, por 
meio da problematização sobre as condições de vida e existência, para o desenvolvimento da consciência crítica, capaz de promover outras formas de ver e de situar-se no mundo, para transformá-lo (LAMARÃO; ABREU; LATTMAN; FERNANDO, 2001).

Vale lembrar que até a Constituição Federal de 1988 (CF/1988) os brasileiros que não sabiam ler e escrever não podiam votar, daí a suposta ameaça da Campanha Nacional de Alfabetização para o país da época que, mesmo em pouco tempo de existência, mostrou a sua grandiosidade. Nas palavras de Freire (Freire apud GADOTTI; ABRAÃO, 2012, p.88),

Foi pouco mas deu para implantar a coisa em todo o país. O negócio era tão extraordinário que não podia continuar. Num estado como Pernambuco, que tinha na época o número aproximado de 800 mil eleitores, em um ano era possível passar para 1 milhão e 300 mil.... e assim em todos os estados do Brasil... ora, isso pesava demais na balança do poder. Era um jogo muito arriscado para a classe dominante.

Quando houve o golpe civil-militar de 1964, que depôs o presidente João Goulart e privou da liberdade e da expressão Paulo Freire e centenas de brasileiros vítimas da ditadura desse período, tais experiências reforçariam ainda mais a crença do autor na defesa de uma educação libertadora e na urgência da erradicação absoluta do analfabetismo como uma chaga social e cultural a ser extirpada.

Preso e depois exilado, por 16 anos (1964-1980) o andarilho Paulo Freire passou por diferentes países, colaborando com governos e movimentos populares (sobretudo, em países de ex-colônias), atuou no Conselho Mundial de Igrejas (em Genebra) e foi professor em universidades estrangeiras. No seu retorno ao país, em 1980, Freire trouxe esperança e energia renovadas para a educação pública em um contexto de transição e de crença nos valores democráticos, como docente em universidades e, especialmente, aceitou o convite, em 1989, da prefeita Luiza Erundina, do Partido dos Trabalhadores (PT) - recém eleita, à época - para assumir a Secretaria Municipal de Educação (SME) de São Paulo. Ao aceitar tão importante desafio público, de ser responsável pela Educação da segunda maior cidade da América Latina, de antemão, anunciou que não ficaria durante toda a vigência do mandato (de quatro anos) e que criaria as condições para a continuidade pela equipe de trabalho, na intenção coletiva de "mudar a cara da escola da cidade", ficando na função por dois anos e cinco meses.

\section{Indissociabilidade entre pensar e fazer}

Nesse período, de Paulo Freire gestor público em São Paulo, foi possível ver reafirmada sua teoria educacional que tem raízes humanistas, realçando a impossibilidade da neutralidade da educação e dos educadores nas dimensões: i) epistemológicas: pelo ato de conhecer como construção e reconstrução de saberes, pela curiosidade epistemológica, pela indissociabilidade entre teoria e prática e entre reflexão e ação; ii) antropológicas: 
considerando o sujeito individual e coletivo e produtor de cultura e o conhecimento dinâmico que se reinventa; iii) políticas: pelo envolvimento da ética e da responsabilidade do educando e do educador (FREIRE, 2003).

Em um município que na época contava com 703 escolas de educação básica (predominantemente de educação infantil e de ensino fundamental), 720 mil estudantes e 40 mil funcionários (equiparável à dimensão educacional de muitos países), Paulo Freire encontrou carências generalizadas na rede pública municipal, entre outras, com mobiliário deficitário, prédios mal-conservados e crianças fora da escola (FRANCO, 2014). Diante desse quadro iniciou um processo de diagnóstico, com visitas às escolas e escuta apurada e diálogo com servidores públicos e população, conjugado ao debate com universidades para o processo formativo dos educadores e com movimentos sociais para a implantação do Movimento de Alfabetização de Adultos (Mova/SP), que contou também com formação específica para os educadores e infraestrutura necessária para a criação dos ambientes de aula. Como marca de governo deixou a crença no processo coletivo de busca, de sujeitos que investigam suas práticas, que são e estão no mundo, ao mesmo tempo que era estimulada a emergência e a visibilidade das realidades e das singularidades das escolas, entendendo e provocando alteridades e reflexões acerca da dimensão opressora que se hospeda em cada um.

"É fundamental diminuir a distância entre o que se diz e o que se faz, de tal forma que, num dado momento, a tua fala seja a tua prática" (FREIRE, 2003, p. 61). Por um olhar hoje distanciado (ou "ad-mirado", pelas palavras de Freire), tal frase pode servir para resumir o Paulo Freire gestor público. Tratou-se, nessas diferentes experiências de gestão pública, de Pernambuco e Brasília a São Paulo, passando pelas aprendizagens do exílio, em que foi possível construir a maior parte de sua produção teórica, da reafirmação da dimensão do inacabamento humano e desejoso de ser mais, quando, em geral, a realidade brasileira reserva à maioria das pessoas, a condição de ser menos.

Junto com o processo de diagnóstico, Freire instigou - de princípio - os profissionais da educação do município de São Paulo e a população envolvida ao debate sobre o Regimento Comum das Escolas, com um documento-base, na intenção de problematizar as concepções de educação para a construção coletiva de uma escola pública, democrática e popular, por meio de uma dinâmica de idas e vindas de problematizações e sugestões sobre o documento, das escolas para a estrutura central, entendendo que as escolas não seriam uniformizadas, mas que, por meio do Regimento Comum seriam garantidas as feições próprias de cada unidade, preservados os princípios da administração municipal.

O cuidado com a qualidade das relações, a problematização, o diálogo como fundamento e meio privilegiado para a convivência humana, o envolvimento de educandos e educadores como sujeitos históricos aprendentes foram ações importantes nesse período que contou como eixos centrais: a) A democratização da gestão: por meio da reorganização dos Conselhos de Escola, dos Grêmios Estudantis, do Regimento Comum das 
Escolas, da partilha de poder pedagógico entre escola e comunidade e da criação dos Núcleos de Ação Educativa que vieram substituir as antigas Delegacias de Ensino, instâncias administrativas intermediárias, que tinham caráter de vigilância e de fiscalização do trabalho nas escolas; b) O acesso e a permanência dos estudantes: alcançadas pela ampliação de vagas, pela implantação dos ciclos de aprendizagem e pelas salas de recursos para estudantes com dificuldades de aprendizagem e com necessidades educacionais especiais (integradas às salas regulares); c) A qualidade da educação: entendida como processo contínuo e de construção coletiva, por meio do Movimento de Reorientação Curricular, numa perspectiva interdisciplinar, pela formação permanente dos educadores por meio dos Grupos de Formação (em geral, com dinâmicas semelhantes à dinâmica dos Círculos de Cultura, por meio da auto-formação, da formação cooperada e da reflexão sobre as práticas), o Plano de Carreira Docente (envolvendo jornada de trabalho e melhoria salarial); o Estatuto do Magistério; d) A Educação de Jovens e Adultos: na forma de parceria com movimentos sociais e organizações da sociedade civil para implantação do Mova, na intenção de minimizar os índices de analfabetismo na cidade e de promover o estreitamento das relações entre as escolas e a educação popular como forma de aumento da participação dos ci6dadãos na esfera pública (FRANCO, 2014). Nas orientações de SME, à época, era frequente Paulo Freire gestor perguntar à rede pública municipal de ensino: a favor de que, de quem e contra que e contra quem se faz a educação?

Com a saída de Paulo Freire de SME, em 1991, o trabalho teve continuidade com Mario Sergio Cortella, que fazia parte da equipe e que a manteve até o final da gestão, em 1993. Na eleição que se seguiu, como acontece historicamente com as políticas públicas no País, houve a descontinuidade de vários projetos iniciados por Freire e sua equipe, mas outros foram aprimorados devido à resistência de grupos de educadores e de escolas, que se mantiveram e se mantêm firmes nos propósitos freirianos, complementados com outras teorias.

É o caso, por exemplo, de escolas que foram reconhecidas pela Secretaria Municipal de Educação de São Paulo e pelo Conselho Municipal de Educação (após mais de duas décadas) como escolas com projetos pedagógicos especiais e que contam com reorganização de tempos, espaços, abertura e diálogo com o território, focadas na inclusão e no direito à educação, servindo de influência para outras experiências (CONSELHO MUNICIPAL DE EDUCAÇÃO- SP, 2015).

É no livro Pedagogia da Esperança que Freire (1992) - em um outro contexto do País - propõe um reencontro com a Pedagogia do Oprimido, estimulando-nos a pensar que a mudança é sempre possível e se as desigualdades e as injustiças são construções humanas, a igualdade e a justiça também o são, relembrando fatos do exílio, as dificuldades, mas também as aprendizagens e saberes que se entrelaçaram culturalmente, tendo a esperança como mola propulsora, o encantamento com a vida, pela linguagem, pelo diálogo e pela crença fortalecida de que a educação, sozinha e isolada, não transforma o mundo, mas que as transformações implicam processos educativos - e que não basta denunciar 
- há que se anunciar saídas, visualizando os 'inéditos viáveis' (como ações educacionais gestadas por meio da consciência crítica, que ainda não se concretizaram e que se anunciam como postura decidida frente ao mundo).

\section{Considerações finais}

O legado Freiriano em tempos pandemônicos (do Covid19) sinaliza que é preciso denunciar as trágicas desistências e impossibilidades de ser mais, seja por negligência das autoridades políticas, seja pela condição de subalternidade que o país atravessa em termos culturais e no âmbito internacional.

As condições de enfrentamento desse estado de coisas nos animam a anunciar a Pedagogia da Esperança na luta contra a campanha nefasta de "Paulo Freire - o educador proibido de educar", ao contrário - torna-se imperativo anunciar (nas frestas dos acontecimentos atuais) e na interpelação da história as brisas de vento e de ar necessárias para respirar e continuar a luta "esperançosa" e não "na espera" - com o reconhecimento que se faz crescente da importância da escola pública - como instituição que alcança a maioria da população cotidianamente e que, no cenário atual, se reinventa pela práxis e pelo exercício do potencial político pedagógico da resistência, contra o discurso de ódio, a a-historicidade e a tentativa de um segundo exílio de Paulo Freire (agora das ideias), com respostas de solidariedade, de afeto e pela convicção de que ninguém pode ficar para trás.

Ainda no caminho do anúncio, uma possível via para a superação desse quadro seria, em primeiro lugar, compreender os projetos e as narrativas em disputa. De um lado, os defensores da escola pública como direito (desde os Pioneiros de 1932³) e, de outro, os defensores da educação como mercadoria, de âmbito privado - por influência de políticas neoliberais com ênfase nos ganhos de mercado e na financeirização ${ }^{4}$ - e, ainda, entender, com Paulo Freire, a favor de que, de quem e contra o que e contra quem estão os projetos das escolas domiciliares, das tentativas de massificação da Educação a Distância, da militarização das escolas, entre outros apresentados pelo atual (des)governo; e, mais que compreender, disputar espaços nessas narrativas.

Em segundo lugar, intensificar a luta (incansável e inadiável) para que a educação seja prioridade dos governos, com ações intersetoriais e interseccionais (aprendendo com os movimentos sociais e coletivos que não é possível tratar de políticas de igualdade ou equidade em qualquer área, sem transversalizar as causas da desigualdade no país), o que envolve o enfrentamento de problemas relativos a raça, gênero, etnia e classe, superando políticas focalizadas com políticas de caráter universalizante.

Enfim, estamos diante do desafio de consolidar o compromisso ético com a humanização - reinventando formas escolares, ao se reconhecer e valorizar a educação que acontece também fora das escolas - de modo a que as escolas e o desejo de conhecer 
façam sentido aos sujeitos (inacabados e que podem sempre 'ser mais'), tanto os sujeitos que tomam parte das instituições escolares, como os sujeitos concretos do seus territórios de pertença, construindo outros valores sobre o ensinar-aprender e a educação integral (de modo a contribuir para o resgate da dignidade, da integralidade e da cidadania dos sujeitos), estimulando o trabalho coletivo, procurando saber quem são os estudantes, suas famílias, realidades, saberes e necessidades, como condição para essa reinvenção.

Tal compromisso ético passa pela formação de professores em contextos aprendentes e pela abertura das escolas para os territórios (CANÁRIO, 2006; FULLAN; HARGREAVES, 2000; FORMOSINHO; MACHADO, 2009; OLIVEIRA-FORMOSINHO; FORMOSINHO, 2008), afirmando convicções que possam impactar positivamente e contribuir para a minimização das desigualdades sociais (e educacionais), dar respostas aos desafios socioambientais e a herança patriarcal e autoritária ainda muito presente entre nós, transitando da solidão (causada pelo isolamento social atual) para a solidariedade, como forma de interpelar a história, e dar respostas humanas em contextos desumanos.

Nas palavras finais em Pedagogia do Oprimido, escrito no Chile, como campo de experiências, de estudos, de reflexões e de práticas com trabalhadores rurais e urbanos, o que aguçou sua percepção acerca das causas das desigualdades sociais, Freire assinala que "se nada ficar destas páginas, algo, pelo menos, esperamos que permaneça: nossa confiança no povo. Nossa fé nos homens, na criação de um mundo em que seja menos difícil amar." (FREIRE; MAFRA; ROMÃO; GADOTTI, 2013, p. 92).

Expressão mais do que atual e necessária nesses tempos de urgências e de carências...

Recebido em 19/07/2020. Aprovado em 05/08/2020.

\section{Notas}

1 Segundo o IBGE, analfabeto é a condição de uma pessoa que não sabe ler nem escrever. Analfabeto Funcional se aplica a uma pessoa que lê e escreve, mas não consegue compreender e interpretar a comunicação escrita.

2 Sistema 'S': Sistema Não Governamental criado pelo Governo Getúlio Vargas (década de 1940) e que envolve instituições ligadas à indústria, entre elas o Serviço Social da Indústria (Sesi), o Serviço Social de Aprendizagem Comercial (Senac) e o Serviço Social do Comércio e Serviços (Sesc).

3 Pioneiros da Escola Nova, movimento de intelectuais e educadores do período da República, expresso no Manifesto dos Pioneiros da Educação Nova (1932), que defendiam uma escola pública única, obrigatória, laica e gratuita. Tinha como expoentes Anísio Teixeira, Lourenço Filho, Fernando de Azevedo, entre outros.

4 Por mercantilização e financeirização entende-se o tratamento da educação como mercadoria por instituições nacionais ou internacionais (privadas), com franca expansão no País, a partir de 1990, de início com presença maior no ensino superior, muitas pertencentes a grandes conglomerados econômicos e expandindo-se, posteriormente, para a educação básica, conjugado a oferta de "produtos" educacionais por corporações, com ações na Bolsa de Valores e no capital especulativo. 


\section{Referências}

AVRITZER, Leonardo. O pêndulo da democracia: uma análise da agitação que marca nosso ambiente político desde as manifestações de 2013. São Paulo: Todavia, 2019.

AVRITZER, Leonardo. Impasses da democracia no Brasil. Rio de Janeiro: Civilização Brasileira, 2016.

ALGEBAILE, Evelina. Escola Pública e Pobreza no Brasil: a ampliação para menos. Rio de Janeiro: FAPERJ; Lamparina, 2009.

BRASIL. Lei Federal n. 12.612/2012 - declara Paulo Freire Patrono da Educação Brasileira. Disponível em: http://portal.mec.gov.br/index.php?option=com_docman\&view=download\&alias=10562-16-04-12-linkleipaulofreire\&category_slug=abril-2012-pdf\&Itemid=30192. Acesso m 10 de julho de 2020.

CANÁRIO, Rui. A escola tem futuro? Das promessas às incertezas. Porto Alegre: Artmed, 2006.

CONSELHO MUNICIPAL DE EDUCAÇÃO DE SÃO PAULO. Parecer n. 433 de 28/08/2015 - Projeto

Político Pedagógico Especial. Disponível em: http://www.mprj.mp.br/documents/2018457474/Projeto_ pedagogico_da_EMEF-Pres_Campos_Salles.pdf. Acesso em 10 de julho de 2020.

DUBET, F. O que é uma escola justa? a escola das oportunidades. São Paulo: Cortez, 2008.

FREI BETTO. Carta aos amigos e amigas do exterior. Carta Maior, 17/07/2020. Disponível em: https://www.cartamaior.com.br/?/Editoria/Sociedade-e-Cultura/Carta-aos-amigos-e-amigas-doexterior/52/48173. Acesso em 18 de julho de 2020.

LAMARÃO, Sergio Tady de Neimeyer; ABREU, Alzira Alves de; LATTMAN, Wetman; FERNANDO, Israel Beloch. Dicionário Histórico Biográfico Brasileiro pós 1930. 2ª ed. Rio de Janeiro: Ed. FGV, 2001.

FORMOSINHO, João; MACHADO, Joaquim. Equipas Educativas: para uma nova organização da escola. Porto: Porto Editora, 2009 [Colecção Infância].

FRANCO, Dalva Souza. A gestão de Paulo Freire à frente da Secretaria Municipal de Educação de São Paulo (1989 - 1991) e suas consequências. Pro-Posições, Campinas, v. 25, n. 3 (75), p. 103-121, set./dez. 2014.

FREIRE, Paulo; MAFRA, Jason Ferreira; ROMÃO, José Eustáquio; GADOTTI, Moacir (Projeto editorial, organização, revisão e textos introdutórios). Pedagogia do Oprimido (o manuscrito). São Paulo: Editora e Livraria IPF; Universidade Nove de julho; DF: Ministério da Educação, 2013.

FREIRE, Paulo. Pedagogia da Autonomia: saberes necessários à prática educativa. 27ª ed. São Paulo: Paz e Terra, 2003.

FREIRE, Paulo. Pedagogia da Esperança: reencontro com a Pedagogia do Oprimido. Rio de Janeiro: Paz e Terra, 1992.

FREIRE, Paulo. Pedagogia do Oprimido. Rio de Janeiro: Paz e Terra, 1978.

FULLAN, Michael; HARGREAVES, Andy. A escola como organização aprendente: buscando uma educação de qualidade. $2^{\underline{a}}$ ed. Tradução de Regina Garcez. Porto Alegre: Artmed, 2000.

GADOTTI, Moacir; ABRAÃO, Paulo. (Orgs.). Paulo Freire anistiado político brasileiro. Instituto Paulo Freire e Comissão de Anistia, Ministério da Justiça, SP: Educação e Livraria IPF; Brasília: Comissão de Anistia, Ministério da Justiça, 2012. 
INSTITUTO BRASILEIRO DE GEOGRAFIA E ESTATÍSTICA - IBGE - Pesquisa Nacional por Amostra de Domicílio Contínua (PNAD-C), 2019. Disponível em: https:/www.ibge.gov.br/estatisticas/sociais/ populacao/9171-pesquisa-nacional-por-amostra-de-domicilios-continua-mensal.html?=\&t=o-que-e. Acesso em 15 de julho de 2020.

OLIVEIRA-FORMOSINHO, Júlia; FORMOSINHO, João. A investigação-acção e a construção do conhecimento profissional relevante. In.: ESTEVES, Lídia Máximo. Visão panorâmica da investigaçãoacção. Porto: Porto Editora, 2008, p. 7-14.

OXFAM BRASIL. Um retrato das desigualdades brasileiras, 2018. Disponível em: https://www.oxfam. org.br/um-retrato-das-desigualdades-brasileiras/. Acesso em 10 de julho de 2020.

SOUSA-SANTOS, Boaventura de. Na oficina do sociólogo artesão: aulas 2011-2016. São Paulo: Cortez, 2018. 